\title{
Gene Expression of MicroRNA-370 in Some Iraqi Women with Breast Cancer
}

\author{
Wafaa Sabri Mahood \\ wafa.sabry@yahoo.com \\ Department of Biology, College of \\ Education for Pure Science, University \\ of Baghdad, Baghdad, Iraq
}

\author{
Maryam Jasim Hasan \\ meryamej526@yahoo.com \\ Department of Biology, College of \\ Education for Pure Science, \\ University of Baghdad, Baghdad,
}

\author{
Mohammed Jasim Mohammed \\ mohamed.jasim.mj@gmail.com \\ Kindy Hospital, Baghdad, Iraq
}

\begin{abstract}
Breast cancer becomes a major threat to female health, many reports refer to a high incidence of breast cancer in Iraq; especially, in the last years. The micro RNA-370 molecules have not been reported in Iraqi cancer patients. Our objective in this study was to identify the expression of micro RNA-370 molecules in breast cancer patients as an early detection biomarker of breast tumors and detect its relation with clinicopathological characters of breast cancer patients. Fifty fresh tissue samples were collected from benign and malignant breast patients in addition to ten normal tissue samples collected as a control group, the age ranged was(19 - 77) years for patients. The miR-370 gene expression level was measured by the quantitative real-time reaction (qRT-PCR). Our results demonstrate a high expression ofmiR370 in benign and malignant tissues. The miR-370 expression level was inversely correlated with the age of the patients. It was a significant relation of miR-370 gene expression on the left side of breast malignant (p- 0.05). In conclusion, significantly associated with high miR-370 expression were found depending on age, tumor location, tumor type, and stage of differentiation. The upregulation of miR-370 gene expression in benign lesions and breast cancer tissue can be applied as a biomarker for early breast cancer detection.
\end{abstract}

Keywords: Gene Expression, microRNA-370, Breast Cancer, Benign, Iraq, qRT-PCR.

\section{Introduction}

Breast cancer is the second leading cause of death among women worldwide. It is the most common tumor in the United States, accounting for $14 \%$ (1.68 million) of all newly diagnosed cancers, about $40.290 \%$ of all deaths from cancer [1]. It is the most prevalent tumor among females in Iraq and it is diagnosed at advanced stages among young women causing short survival, making it a great challenge facing public health in Iraq and the world [2]. Breast tumors are a heterogeneity disease, and its diagnostic and clinical findings are widely divergent and biomarkers or diagnostic methods that are used to predict breast tumors may be of limited use [3]. The microRNAs are small uncoded molecules of RNAs consisting of 18-25 nucleotides. They regulate gene expression by partial matching with untranslated region 3 '(UTR), form RNA Induced Silencing Complexes (RISCs) to lyses the target mRNAs or inhibit their translation respectively. They also provide a rapid mechanism to regulate the gene expression of a large number of genes [4,5]. Previous studies have suggested that microRNAs play a vital role in the growth and development of breast cancer. The miRNAs For more information about the Conference please visit the websites: 
may act as diagnostic biomarkers for early detection [6,7]. Different level of several miRNA expressions between normal and malignant tissues was observed in different tumor subtypes of breast cancer and age groups in Tsai et al., study. They are found down-regulated of miR335 and miR-145 while up-regulated expression was detected in miR-21, miR-200a, miR200c, and miR-141 for all patients [8]. Quan et al. also reported up-regulated miR-206 and down-regulated miR-145 in breast cancer tissues, which may indicate the prognosis effect of miRNA in patients [9]. A recent study showed that measured miRNA profiles in blood facilitate early detection and less-invasive diagnosis of aggressive type triple-negative breast cancer [10]. One of the rare studies that investigated the miRNA370 in breast cancer is the Iranian study and which was performed by Mollainezhad and his colleagues. They refer to up -regulation (six-fold higher) of miR-370 in breast cancer tissue compared with the normal adjacent tissue. Patient characteristics like stage III, larger tumor size, invasive ductal type, and other features showed a significantly high level of expression in miR-370, suggesting that miR-370 may have an onco-miRNA role. It may be helpful as a diagnostic biomarker and therapeutic if detect its action targets [11]. Another study suggests that miR-370 is associated with gastric carcinoma progression by down-regulating of transforming growth factor $-\beta$ receptor II( TGF $\beta$-RII) and it may be considered as onco-miRNA [12]. Although it has different targets, miR370 - could have an essential role in the reduction of colorectal cancer tumorigenesis by independently targeting epidermal growth factor receptor (EGFR) and PIK3CA via overexpression of miR-370. They cause suppression of the important molecules of the PI3K/AKT/mTOR pathway which is important in most cancer cell characteristics as proliferation, migration, and invasion [13]. The tumor suppressor role of miR-370 also was found in osteosarcoma cells and human prostate cancer as miR-370 could directly target the $3^{\prime}$ UTR of FOXM1 and FOXO1 genes [14.15]. The protein encoded by these genes is a member of the FOX family of transcription factors [16].miR-370 enhanced endometrioid ovarian cancer cell chemosensitivity tocisplatin (CDDP) as well as acts as a tumor suppressor in endometrioid ovarian cancer cells [17]. In a recent study (published in 2018) the miR-370 encoded gene stimulated apoptosis in the colon cells with a direct effect on mouse double minute-4 (MDM4). The miR-370 expression was low in the tumor tissue and the expression of miR-370 was linked conversely to the stages of the disease. The higher progression of the disease, the lower level of miR-370 expression. These results suggest a new biomarker in the diagnosis and treatment of colorectal tumors based on the miR-370 molecules [18]. The current study was aimed to identify miR-370 expression as a biomarker in some patients of Iraqi women with breast cancer and its relation with clinicopathological characters.

\section{Materials Method}

\subsection{Patient tissue specimens}

The samples were obtained from breast tumor patients who underwent to the Medicine city Hospital in Baghdad and private laboratories from October 2017 to April 2018. All received chemotherapy or radiotherapy patients were excluded. Fifty tissue samples were collected, including 25 tissue samples from each benign and malignant breast cancer patient, besides ten samples from normal tissue were used as a control group. The age range of patients and control group (19-77) years and (22-76) years respectively. The samples were stored in the For more information about the Conference please visit the websites: 
deep freeze until RNA extraction. The approval by the Ethics Committee of the Ministry of Health in Iraq and Baghdad University was obtained to conduct the research.

\subsection{The miR-370 Expression Analyses}

Total RNA was extracted from tissue samples using (miRNeasy Mini Kit) (QIAgen, Germany) (Cat No. /ID: 217004) according to the manufacturer's procedure. The miScript II RT kit and HiSpec buffer (QIAgen Germany) (Cat No. /ID: 218161), were used to syntheses for total RNA reverses transcribed. The total volume of reaction was $10 \mu \mathrm{l}$ including $(2 \mu \mathrm{l} 5 \mathrm{x}$ miScript HiSpec Buffer, $1 \mu 1$ of 10x miScript Nucleics Mix, $4 \mu 1$ of RNase-free water RNase, $1 \mu 1$ of miScript Reverse Transcriptase Mix and $2 \mu 1$ of Template). Final cDNA samples were stored at a $-20^{\circ} \mathrm{C}$. The expression level of miR-370 gene was detected by RT-qPCR technique using the master mix miScript SYBR Green PCR (QIAgen) kit (Cat No. /ID: 218073). The relative amount of miR-370 was normalized against U6 small nuclear (sn) RNA (as an internal control). The primers used for qRT-PCR reactions as described by Saberi et al., for U6 [19] and Mollainezhad et al., for miR-370 [11] (Table 1). All primers were purchased from (Alpha DNA Company, Canada). The total volume of qRT-PCR reaction was $10 \mu 1$ and it contained $5 \mu 1$ master mix, $1 \mu 1$ for each forward and reverse primers, $2 \mu 1$ RNase free water, and $1 \mu \mathrm{l}$ of cDNA template. The PCR condition was $95^{\circ} \mathrm{C}$ for 10 minutes, followed by 40 cycles at $95^{\circ} \mathrm{C}$ for 15 seconds for denaturation then 20 seconds at $55^{\circ} \mathrm{C}$ for annealing, finally 30 seconds at $72^{\circ} \mathrm{C}$. The threshold cycle $(\mathrm{Ct})$ is described as the cycle number at which the fluorescence level will pass into the assumed threshold. To analyze miR-370 expression, the fold-change of gene expression between cancer tissues and normal breast tissue control was calculated by the $2^{-\Delta \Delta \mathrm{Ct}}$ method, in which $\Delta \Delta \mathrm{Ct}=(\mathrm{CtmiR}-370$ - CtU6 snRNA) mean tumor(CtmiR-370 - CtU6 snRNA) means normal. The relative expression levels of miRNAs in cancer compared to normal tissue (control group) were selected and calculated using the method of $2^{-\Delta \Delta C t}$ [20].

Table 1. Sequence-specific primers of qRT-PCR reactions.

\begin{tabular}{|c|c|}
\hline Molecule & Sequences \\
\hline MicRNA-370 (Forward) & 5'-GCCTGCTGGGGTGGAACCTGGTAA-3' \\
\hline MicRNA-370 (Reverse) & 5'- GCGAGCACAGAATTAATACGAC-3' \\
\hline $\begin{array}{ll}\text { U6snRNA } & \text { (Forward) } \\
\end{array}$ & 5'-CTCGCTTCGGCAGCACA-3' \\
\hline U6snRNA & 5'-AACGCTTCACGAATTTGCGT-3' \\
\hline
\end{tabular}

\subsection{Statistical analysis}

Differences in the mean between miR-370 expression in the sample of the breast (benign and malignant) and control group. As well as the relation of miR-370 expression with clinical parameters was analyzed using $\chi^{2}$ and Student's t-test. All tests were performed using SPSS 16 and a $\mathrm{P}<0.05$ was supposed to be statistically significant.

\section{Results and Discussion}

\subsection{Patients clinical characteristics}

Clinical characteristics of breast cancer patients such as tumor type, grade, differentiation, and tumor site are shown in (Table 2). The study group consists of 50 patients including 25 breast benign lesion patients with an average age of 34 years range (19-57) years and 25 breast cancer patients with an average age of 50 years, range (35-77) years. Also, ten normal samples with 38 years of age means were used as the control group. Depending on For more information about the Conference please visit the websites: 
age, $52 \%(13 / 25)$ of females less than fifty years, no significant difference was identified between the groups regarding ages $(\mathrm{P}=0.325)$. There was a high rate of $(80 \%(20 / 25)$ of patients enrolled in this study with invasive carcinoma. According to tumor grade, $48 \%$ and $36 \%$ were grade 1 and grade 2 respectively. While $84 \%$ of patients were recorded with a moderately differentiated tumor.

Table 2. Clinical characteristics of patients with breast malignancies.

\begin{tabular}{|c|c|c|}
\hline Characteristics of patients with cancer & Number & Percentage\% \\
\hline Total number of patients & 25 & 100 \\
\hline \multicolumn{3}{|l|}{ Average age 50} \\
\hline $\begin{array}{l}<50 \\
<50\end{array}$ & 13 & 52 \\
\hline$>50$ & 12 & 48 \\
\hline \multicolumn{3}{|l|}{ Type of tumor } \\
\hline Lobular carcinomas & 2 & 8 \\
\hline Ductal carcinomas & 3 & 12 \\
\hline Invasive carcinomas & 20 & 80 \\
\hline \multicolumn{3}{|l|}{ Grade } \\
\hline Grade I & 12 & 48 \\
\hline Grade II & 9 & 36 \\
\hline Grade III & 4 & 16 \\
\hline \multicolumn{3}{|l|}{ Differentiation } \\
\hline Moderately & 21 & 84 \\
\hline Well & 4 & 16 \\
\hline Poorly & 0 & 0 \\
\hline \multicolumn{3}{|l|}{ Tumor site } \\
\hline Left & 10 & 40 \\
\hline Right & 10 & 40 \\
\hline Un known & 5 & 20 \\
\hline
\end{tabular}

\subsection{The miR-370 expression level in breast benign lesions}

The study was conducted to investigate the miR370 expression levels in breast benign and malignant tumors compared with normal breast tissues. The PCR products were pure and homogeneous; indicating by melting curves of miR-370, they are showed as sharply defined melting curves with narrow peaks (Figure 1). Expression of miR-370 in 25 breast benign patients (breast lesion) was detected, the results showed an increase of fold miR-370 expression in those patients. The mean of fold expression was 8.2 in comparison with 1.6 means for normal tissue with standard error (Mean \pm SE- 9.38 \pm 4.32 ) with significant differences were found depending on age $(\mathrm{P}=0.047)$ in breast lesion. There was a high expression level of miR-370 in the right site, the mean of fold expression was 11.38 (SE 1.6 \pm 0.805 ) while no significant differences depending on the site of breast benign were found $(\mathrm{P}=0.2)$.

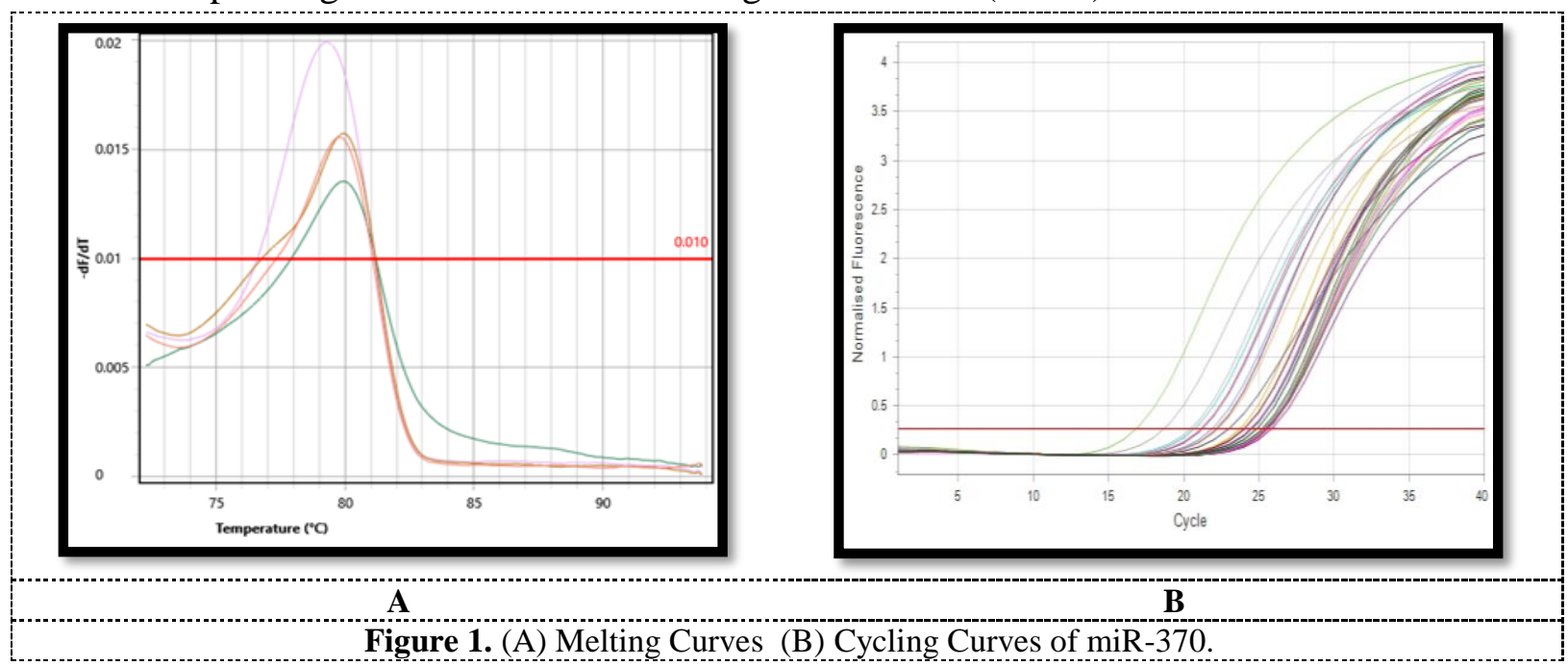

For more information about the Conference please visit the websites: 


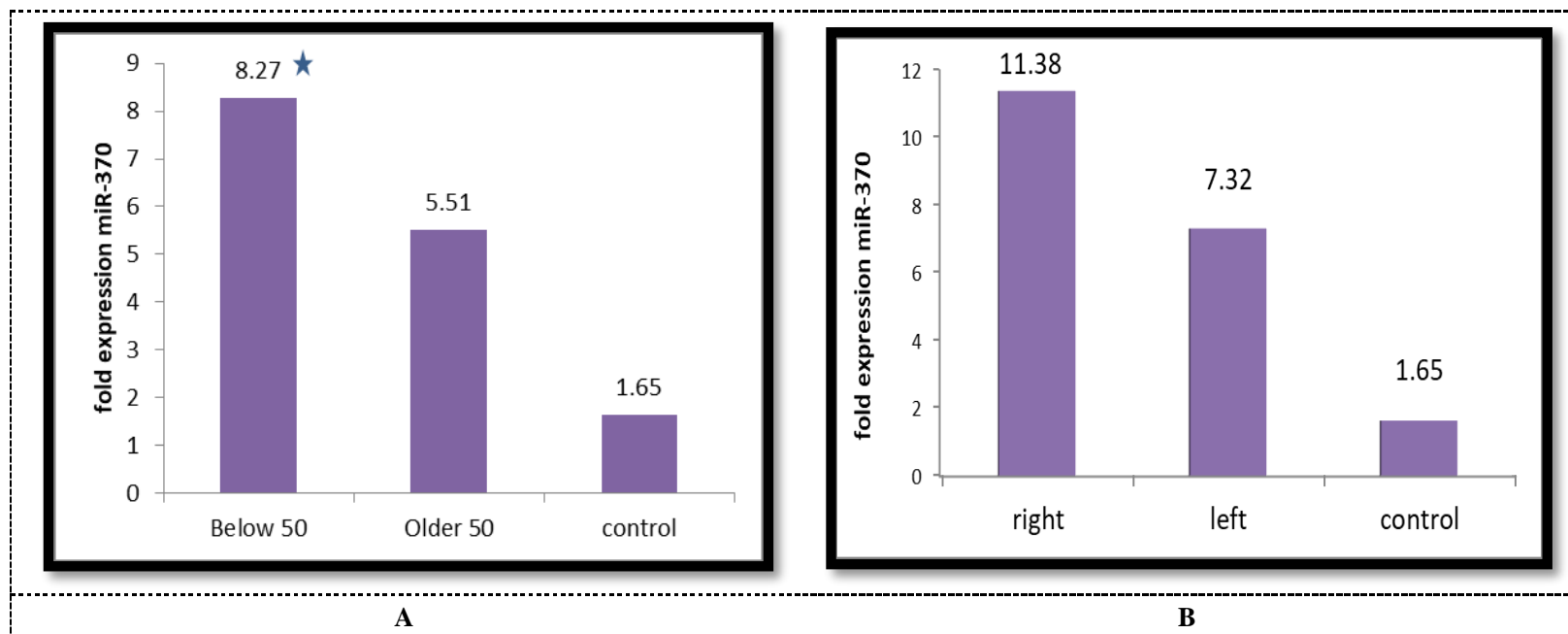

Figure 2. Gene expression of miR-370 in benign tumors (A) High level of miR-370 expression in age below 50 years depending on age $(*)$ significant difference $(p \leq 0.05)$, (B): High level of miR-370 expression in right and left site depending on location compared with control group.

\subsection{The miR-370 expression level in breast cancer patients}

The fold expression level was increased by 8.56 in less than fifty years old patients. In the older 50 years of patients, the fold expression level was 2.61 compared with the fold expression level of control samples at 1.65. It was observed that the significant difference between the control group and patients with age of fewer than 50 years $(\mathrm{P}=0.03)$ was $(\mathrm{SE}-6.91 \pm$ 2.92). Whilst the significant difference between the younger and older ages of 50 years $(\mathrm{P}=$

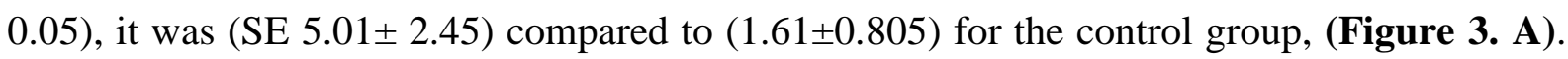
Concerning the tumor site, the fold expression level of the miR-370 was 5.46 and 3.81 on the left and right side respectively compared to the fold expression of the control samples by 1.65. There was a significant difference between the left group and the control group $(\mathrm{P}=0.05)(-$ $4.53 \pm 2.12$ ) (Figure 3. B). Other tumor characteristics like tumor type and tumor grade are summarized in (Figures 3. C and D). A high rate of invasive carcinoma as tumor type $80 \%$ (20/25) in breast patients showed up-regulated expression of miR-370 gene expression (Mean $\mathrm{SE} \pm 8.57 \pm 2.099)$ more than a control group. No significant association of miR-370 expression with tumor type, $(\mathrm{P}=0.2)$ although high levels of fold expression (7.53 and 6.09). Upregulated gene expression of miR-370, also was showed (SE 7.46 \pm 3.39 ) comparable with the control group in tumor grade II. Results showed no significant association was observed in miR-370 expression with tumor grade $(\mathrm{P}=0.5)$ despite a high level of fold expression $(8.67$ and 6.59) in grades 1 and 2 respectively compared to the control group. No significant differences of the miRNA370 expression depending on differentiation were observed. Despite the increasing level of miRNA370 fold expression 7.8 (SE 9.96 \pm 4.04$),(\mathrm{P}=0.4)$ in moderately differentiated in comparison to the control group (SE 1.68 0.77) (Fig. 3. E).

For more information about the Conference please visit the websites: 
Ibn Al-Haitham Journal for Pure and Applied science https://doi.org/10.30526/2021.IHICPAS.2652

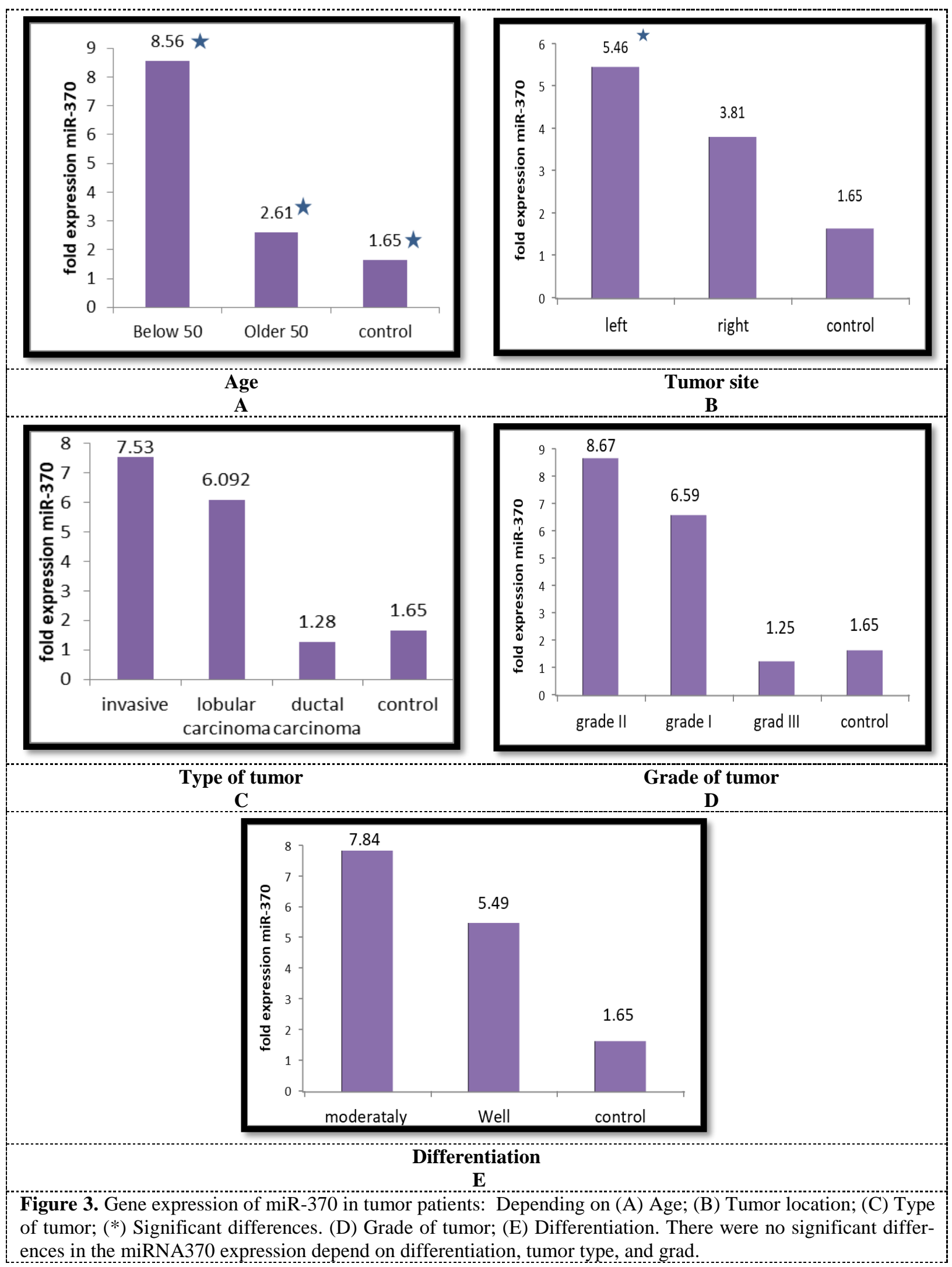

\subsection{Comparison between the miR-370 expressions in benign and tumor breast tissues}

The miR-370 expression was up-regulated in $60 \%$ (30/50) of benign and malignant breast patients tissue compared with normal tissue, with an average increase of 7.2 fold ex-

For more information about the Conference please visit the websites:
http://ihicps.com/
B i o l o g y | 62 
pression with significant differences $\mathrm{P}=0.03$ (Figure 4).

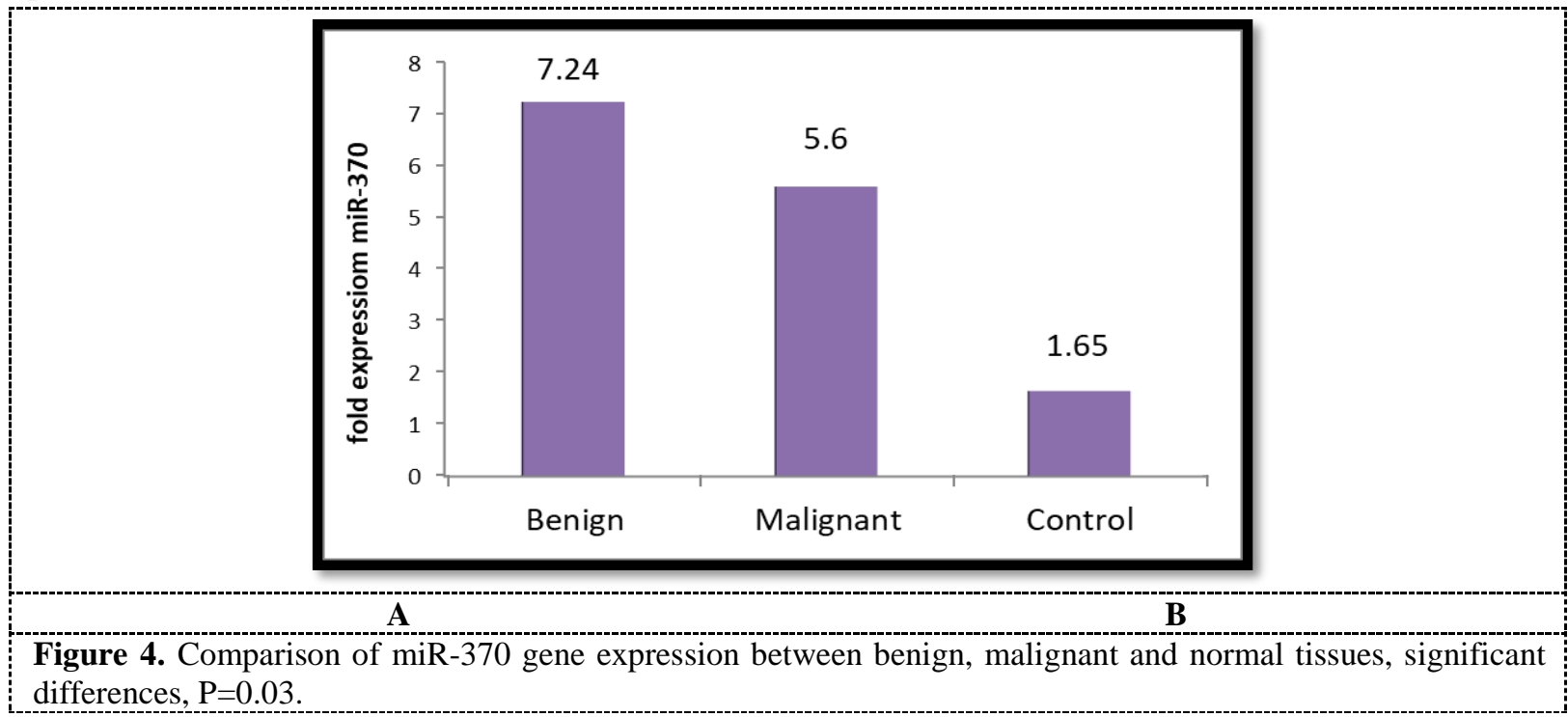

\section{Discussion}

The discovery of small RNA fragments led to a global research effort to determine its role in cancer [21]. It has been shown to regulate molecular pathways in cancer by targeting various carcinogenic and tumor suppressor genes. It has a role in stem cell biology, vessel formation, Epithelial-Mesenchymal transition, proliferation, and resistance to treatment [21, 22]. Molecular research on miR-370 has been controversy about its role in carcinogenesis. Several studies have shown that this molecule acts as oncomiRNA toward advanced stages of cancer, such as Wilm tumor which is kidneys cancer usually occurs in children) [23], Gastric cancer [24], as well as acute myeloid leukemia (AML) [25]. All of which may occur with the miR-370 effect as an oncogene. In contrast, it may act as an inhibitor of tumors or tumor suppressor genes in laryngeal cell carcinoma and biliary duct cancer [26, 27]. This study highlights the ability of the miR-370 gene expression in benign and malignant tumors to serve as a biomarker in breast cancer patients. This work is considered as the first research conducted to investigate the level of miR-370 expression based on SYBR-Green quantitative qRT-PCR in benign and malignant Iraqi breast patients. Our previous study was showed upregulate of the miR-328 gene expression level in both benign lesions and breast cancer, suggesting a miR-328 role as a biomarker for early breast cancer detection [28]. The average age of patients with benign and malignant breast cancer in the present study was 34 and 50 years, $52 \%$ of malignant breast patients were younger than 50 years and $84 \%$ of patients were with moderately differentiated tumors. A high rate $(80 \%)$ of patients were identified with invasive carcinoma, these results agree with the Iranian study [11]. Based on our findings, in all 25 samples of benign tumors, the fold expression level of miR-370 was increased seven times compared with the fold expression level of control samples with a significant association was found in the level of miR-370gene expression between the ages of less than 50 years and control group $(\mathrm{P}=0.047)$. Depending on the location of the tumor, a high level of the miR-370 fold expression was observed on the right side compared with the fold expression for control samples. There was no significant difference between the groups. Alterations of miR-370 gene expression in benign and malignant breast patients give an For more information about the Conference please visit the websites: 
important vision for the miR-370 role in initiating and progressing breast cancer. Significantly associated with high miR-370 expression were found depending on age, tumor location, tumor type, and stage of differentiation. The results indicated that the up-regulated miR-370 can act as oncomiRNA in breast cancer. The overexpression of miR-370 may be responsible for the development of a benign tumor, and the development of breast cancer. Shen with his colleagues observed an increase in miR-370 expression in 60\% of colorectal cancer patients depending on age [18]. Mollainezhad and his group [11] showed increased expression of $\mathrm{miR}-370$ in the first and second grades with no significant relation $(\mathrm{P}=0.297)$ in breast cancer. These results refer to the up-regulated miR-370 that may act as oncomiRNA in breast cancer. The overexpression of miR-370 can be responsible for the initiation of a benign tumor and the development of breast cancer. Significantly associated with high miR-370 expression were found depending on age, tumor location, tumor type, and stage of differentiation. The results indicated that the up-regulated miR-370 can act as oncomiRNA in breast cancer, the overexpression of miR-370 may be responsible for the development of a benign tumor, and the development of breast cancer. Shen with his colleagues was observed an increase in miR370 expression in $60 \%$ of colorectal cancer patients depending on age [18]. Mollainezhad and his group [11] showed an increased expression of miR-370 in the first and second grades with no significant relation $(P=0.297)$ in breast cancer. These results refer to the up-regulated miR-370 that may act as oncomiRNA in breast cancer. The overexpression of miR-370 can be responsible for the initiation of a benign tumor and the development of breast cancer. Increasing evidence showed that miRNAs are involved in cancer pathogens and have given new concepts in the biological pathway to cancer like induced gastric cancer by epigenetic silencing of promoter-proximal $\mathrm{CpG}$ island hypermethylation for miRNA 9 gene [31). This miR-370-induced proliferation by down-regulation of cyclin-dependent kinase inhibitors, p27(Kip1) and p21(Cip1), and the up-regulation of the cell cycle regulator cyclin D1 [32]. Moreover, 10 dysregulated miRNAs were identified in both breast cancer cells and chemoresistant tissues, which might be biomarkers for the chemoresistance prognosis of breast cancer. It is useful for developing new strategies for targeted therapies in chemoresistant breast cancer patients [33]. Another study showed that miR-370 plays an important role in the proliferation of prostate cancer cells and direct inhibition of FOX1, which is associated with cellular functions including cellular growth, differentiation, apoptosis, and angiogenesis [15]. It has been known that miR-370 works either as oncomiR or as a suppressor tumor. The miR-370 molecule, as oncomiR, was found in the Pan et al., study because increased miR-370 expression in liver cancer cell lines may inhibit cell proliferation and induce apoptosis. It may inhibit the histological invasion of the tumor, thus, miR-370 acts as a tumor suppressor in the liver cancer cell lines [34]. Mollainezhad with colleagues has been reported that miR-370 could be considered as a new diagnostic factor in breast cancer as a result of its role as an oncogene, and it may be useful both as a diagnostic agent and in targeted treatment [11]. The effect of miR-370 in cancer is controversial, this may be due to its ability to regulate multiple genetic targets, which makes its function in different roles, yet the function of this molecule depends on the type of cell. 


\section{Conclusion}

The present study suggested that miR-370 may serve as an onco-miRNA. Significantly associated with high miR-370 expression were found depending on age, tumor location, tumor type, and stage of differentiation. The level of miR-370 gene expression can be used as biomarkers for breast cancer.

\section{Acknowledgement}

The authors are grateful for the valuable comments and observations we make in our work.

\section{References}

1. Miller KD, Siegel RL, Lin CC, Mariotto AB, Kramer JL, Rowland, JH, Stein, KD, Alteri R. and Jemal A. Cancer treatment and survivorship statistics, CA Cancer J. Clin. 2016 ,66, 271.

2. Alwan, N.A.S.; Tawfeeq, F.; Maallah, A.S.; Sattar, S.A.; Saleh, W.A. The Stage of Breast Cancer at the Time of Diagnosis: Correlation with the Clinicopathological findings among Iraqi Patients. J. Neoplasm. $2017,2,22$.

3. Imani, S.; Zhang, X.; Hossein, H.; Fu, S.; Fu, J. The diagnostic role of micro RNA-34a in breast cancer: asystematic review and meta-analysis Oncotarget. $2017,8,23177$.

4. Carthew. R.W.; Sontheimer. E.J. Origins and mechanisms of miRNAs and siRNAs. Cell. $2009,136642$.

5. Wang, P.; Chen, L.; Zhang, J.; Chen, H.; Fan, J.; Wang, K.; Luo, J.; Chen, Z.; Meng, Z.; Liu, L. Methylation-mediated silencing of the miR-124 genes facilitates pancreatic cancer progression and metastasis by targeting Rac1. Oncogene. $2014,33514$.

6. Gao, Y.; Cai, Q.; Huang, Y.; Li, S.; Yang, H.; Sun, L.; Chen, K.; Wang, Y. MicroRNA-21 as a potential diagnostic biomarker for breast cancer patients: a pooled analysis of individual studies. Oncotarget 2016, 7, 34498.

7. Xiong, D.D.; Lv, J.; Wei, K.L.; Feng, Z.B.; Chen, J.T.; Liu, K.C.; Feng, Z.B.; Tian, J.; Chen, J.T.; Liu, K.C.; Chen, G.; Luo, D.Z. A nine-miRNA signature as a potential diagnostic marker for breast carcinoma: An integrated study of 1,110 cases. Oncol. Rep. 2017, 37, 3297.

8. Tsai, H.P.; Huang, S.F.; Li, C.F.; Chien, H.T.; Chen, S.C. Differential microRNA expression in breast cancer with different onset age. PloS One. 2018, 13, e0191195.

9. Quan, Y.; Huang, X.; Quan, X. Expression of miRNA-206 and miRNA-145 in breast cancer and correlation with prognosis. Oncol. Lett. 2018, 16, 6638.

10. Kahraman, M.; Röske, A.; Laufer, T.; Fehlmann, T.; Backes, C.; Kern, F.; Kohlhaas, J.; Schrörs, H.; Saiz, A.; Zabler, C.; Ludwig, N.; Fasching, P.A.; Strick, R.; Rübner, M.; Beckmann, M.W.; Meese, E.; Keller, A.; Schrauder, M.G. MicroRNA in diagnosis and therapy monitoring of early-stage triple-negative breast cancer. Sci. Rep. 2018, 8, 11584.

11. Mollainezhad, H.; Eskandari, N.; Pourazar, A.; Salehi, M.; Andalib, A. Expression of microRNA-370 in human breast cancer compare with normal samples. Adv. Biomed. Res. $2016,5,129$.

12. Lo, S.; Chen, J. Overexpression of miR-370 and downregulation of its novel target TGF $\beta$ RII contribute to the progression of gastric carcinoma. Oncogene. 2012, 31, 226.

13. El-Daly, S.M.; Abba, M.L.; Patil, N.; Allgayer, H. miRs-134 and -370 function as tumor suppressors in colorectal cancer by independently suppressing EGFR and PI3K signalling. Sci. Rep. 2016, 20, 24720.

14. Duan, N.; Hu, X.; Yang, X.; Cheng, H.; Zhang, W. MicroRNA-370 directly targets FOXM1 to inhibit cell growth and metastasis in osteosarcoma cells. Int. J. Clin. Exper. Pathol. 2015 ,8, 10250. 
15. Wu, Z.; Sun, H.; Zeng, W.; He, J.; Mao, X. Upregulation of MircoRNA-370 induces proliferation in human prostate cancer cells by downregulating the transcription factor FOXO1. PloS One. 2012, 7, e45825.

16. Ye, H.; Kelly, T.F.; Samadani, U.; Lim, L.; Rubio, S.; Overdier, D.G.; Roebuck, K.A.; Costa, R.H. Hepatocyte nuclear factor 3/fork head homolog 11 is expressed in proliferating epithelial and mesenchymal cells of embryonic and adult tissues. Mol Cell Biol. 1997, 17, 1626.

17. Chen, X.P.; Chen, Y.; Lan, J.Y.; Shen, Z.J. MicroRNA-370 suppresses proliferation and promotes endometrioid ovarian cancer chemosensitivity to cDDP by negatively regulating ENG Cancer Lett. 2014, 353, 201.

18. Shen, X.; Zuo, X.; Zhang, W.; Bai, Y.; Qin, X.; Hou. N MiR-370 promotes apoptosis in colon cancer by directly targeting MDM4 Oncol Lett. 2018, 15, 1673.

19. Saberi, A.; Danyaei, A.; Neisi, N.; Dastoorpoor, M.; Birgani, M.J.T. MiR-328 may be considered as an oncogene in human invasive breast carcinoma IRCMJ. 2016, 18, e42360.

20. Livak, K.J.; Schmittgen, T.D. Analysis of relative gene expression data using real time quantitative PCR and the 2(-Delta Delta C(T)) Method. Methods. 2001, 25, 402.

21. Johnson, S.M.; Grosshans, H.; Shingara, J.; Byrom, M.; Jarvis, R.; Cheng, A.; Labourier, E.; Reinert, K.L.; Brown. D.; Slack. F.J. RAS Is Regulated by the let-7 MicroRNA Family Cell 2005, 120, 635.

22. Ahmad, J.; Hasnain, S.E.; Siddiqui, S.M.A.; Ahamed, M.; Musarrat, J.; Al-Khedhairy. A.A. MicroRNA in carcinogenesis \& cancer diagnostics: A new paradigm. Indian J. Med. Res. 2013, 137, 680.

23. Cao, X.; Liu, D.; Yan, X.; Zhang, Y.; Yuan, L.; Zhang, T.; Fu, M.; Zhou, Y.; Wang, J. Stat3 inhibits WTX expression through up-regulation of microRNA-370 in Wilms tumor. FEBS Lett. 2013, 587, 639.

24. Fan, C.; Liu, S.; Zhao, Y.; Han, Y.; Yang, L.; Tao, G.; Li, Q.; Zhang, L. Upregulation of miR-370 contributes to the progression of gastric carcinoma via suppression of FOXO1. Biommd. Pharmacother. 2013, 67, 521.

25. Zhang, X.; Zeng, J.; Zhou, M.; Li, B.; Zhang, Y.; Huang, T.; Wang, L.; Jia, J.; Chen, C. The tumor suppressive role of miRNA-370 by targeting FoxM1 in acute myeloid leukemia. Molec. Cancer. 2012, 11, 56.

26. Yungang, W.; Xiaoyu, L.; Pang, T.; Wenming, L.; Pan, X. miR-370 targeted FoxM1 functions as a tumor suppressor in laryngeal squamous cell carcinoma (LSCC) Biomed. Pharmacother. 2014, 68, 149.

27. Xu, W.P.; Yi, M.; Li, Q.Q.; Zhou, W.P.; Cong, W.M.; Yang, Y.; Ning, B.F.; Yin, C.; Huang, Z.W.; Wang, J.; Qian, H.; Jiang, C.F.; Chen, Y.X.; Xia, C.Y.; Wang, H.Y.; Zhang, X.; Xie, W.F. Perturbation of MicroRNA-370/Lin-28 homolog A/nuclear factor kappa B regulatory circuit contributes to the development of hepatocellular carcinoma. Hepatology 2013, 58, 1977.

28. Hasen, M.J.; Mahood, W.S. Evaluation of the microRNA-328 gene expression in some Iraqi breast cancer women. J. Pharm. Sci. Res. $2019,11,2347$.

29. Lu, M.; Wang, Y.; Zhou, S.; Xu, J.; Li, J.; Tao, R.; Zhu. Y. MicroRNA 370 suppresses the progression and proliferation of human astrocytoma and glioblastoma by negatively regulating $\beta$ catenin and causing activation of FOXO3a. Exper. Therap. Med. 2018, 15, 1093.

30. Peng, Z.; Wu, T.; Li, Y.; Xu, Z.; Zhang, S.; Liu, B.; Chen, Q.; Tian, D. MicroRNA-370$3 p$ inhibits human glioma cell proliferation and induces cell cycle arrest by directly targeting $\beta$-catenin. Brain Res. 2016 , 1644, 53. 
31. Li, Y.; Xu, Z.; Li, B.; Zhang, Z.; Luo, H.; Wang, Y.; Lu, Z.; Wu, X. Epigenetic silencing of miRNA 9 is correlated with promoter proximal $\mathrm{CpG}$ island hypermethylation in gastric cancer in vitro and in vivo Int. J. Oncol. 2014, 45, 2576.

32. Fan, C.; Liu, S.; Zhao, Y.; Yang, Y.; Tao, G.; Li, Q.; Zhang, L Upregulation of miR-370 contributes to the progression of gastric carcinoma via suppression of FOXO1. Biomed. Pharmacother. 2013, 67, 521.

33. Lv, J.; Xia, K.; Xu, P.; Sun, E.; Ma, J.; Gao, S.; Zhou, Q.; Zhang, M.; Wang, F.; Chen, F.; Zhou, P.; Fu, Z.; Xie, H. miRNA expression patterns in chemoresistant breast cancer tissues. Biomed. Pharmacother. 2014, 68, 935.

34. Pan, X.P.; Wang, H.X.; Tong, D.M.; Li, Y.; Huang, L.H.; Wang, C. miRNA-370 acts as a tumor suppressor via the downregulation of PIM1 in hepatocellular carcinoma. ERMPS. 2007, 21, 1254. 